\title{
Inception of debris avalanches: remarks on geomechanical modelling
}

Abstract Debris avalanches are complex phenomena due to the variety of mechanisms that control the failure stage and the avalanche formation. Regarding these issues, in the literature, either field evidence or qualitative interpretations can be found while few experimental laboratory tests and rare examples of geomechanical modelling are available for technical and/or scientific purposes. As a contribution to the topic, the paper firstly highlights as the problem can be analysed referring to a unique mathematical framework from which different modelling approaches can be derived based on limit equilibrium method (LEM), finite element method (FEM), or smooth particle hydrodynamics (SPH). Potentialities and limitations of these approaches are then tested for a large study area where huge debris avalanches affected shallow deposits of pyroclastic soils (Sarno-Quindici, Southern Italy). The numerical results show that LEM as well as uncoupled and coupled stress-strain FEM analyses are able to individuate the major triggering mechanisms. On the other hand, coupled SPH analyses outline the relevance of erosion phenomena, which can modify the kinematic features of debris avalanches in their source areas, i.e. velocity, propagation patterns and later spreading of the unstable mass. As a whole, the obtained results encourage the application of the introduced approaches to further analyse real cases in order to enhance the current capability to forecast the inception of these dangerous phenomena.

Keywords Landslide A Avalanche · Failure - Entrainment . Modelling

\section{Introduction}

Rainfall-induced landslides of the flow type (Hungr et al. 2001) in granular soils are among the most complex natural hazards due to the variety of mechanisms, which regulate the failure and propagation stages (Cascini et al. 2010; Pastor et al. 2009; Picarelli et al. 2008; Savage and Hutter 1991). Among these, the so-called "debris avalanches" still pose major challenges to researchers and practitioners due to the absence of a unique classification system and a consistent mathematical framework for their analysis.

Referring to the classification of landslides proposed by Hungr et al. (2001), debris avalanches can be defined as "very rapid to extremely rapid shallow flows of partially or fully saturated debris on a steep slope, without confinement in an established channel". These phenomena originate in open slopes, i.e. shallow soil deposits with nearly constant depths and slope angles and they generally occur in $30-45^{\circ}$ hillslopes, involving $1-2 \mathrm{~m}$ thick deposits of coarse grained and cohesionless soils within several environmental contexts. Typical examples are represented by torrent deposits in USA (Costa and Williams 1984), decomposed granitic soils in Japan (Wang et al. 2003), pyroclastic deposits in Southern Italy (Cascini et al. 2008b; Guadagno et al. 2005; Revellino et al. 2004), debris deposits of Valtellina area (Northern Italy) (Chen et al, 2006) and colluvial soils of British Columbia (Hungr et al. 2008).
Independently from the affected environmental context, debris avalanches show a typical triangular shape, somehow similar to snow avalanches (Jamiesion and Stethem 2002), with an uppermost zone of few meters, widths generally below $200 \mathrm{~m}$ and lengths of the source areas from 300 to $500 \mathrm{~m}$; the involved volumes range from a few hundred cubic metres up to several tens of thousands cubic metres (Hungr et al. 2008).

In the scientific literature, distinct triggering mechanisms are indicated for the inception of debris avalanches: (1) the impact of failed soil masses on stable deposits (Costa and Williams 1984; Di Crescenzo and Santo 2005; Guadagno et al. 2005; Hutchinson and Bhandari 1971; Wang et al. 2003); (2) direct rainfall infiltration from the ground surface, locally facilitated by anthropogenic factors such as mountain roads and tracks (Guadagno et al. 2005); (3) karst spring from bedrock as observed for pyroclastic soils in southern Italy (Budetta and de Riso 2004; Cascini et al. 2008b; Cascini et al. 2005; Di Crescenzo and Santo 2005; Guadagno et al. 2005), (4) runoff from bedrock outcrops as evidenced for shallow landslides in cohesionless soils of the Eastern Italian Alps (Tarolli et al. 2008); and (5) multiple failures in the landslides source areas, as recently evidenced by Cascini et al. (2008b). The scientific literature also indicate that (1) all these triggering mechanisms originate small translational slides (Cruden and Varnes 1996); (2) the failed mass increases its volume inside triangular-shaped areas during the so-called "avalanche formation", which is mostly explained referring to soil liquefaction induced by impact loading (Hungr et al. 2008); and (3) soil erosion along the landslide propagation path may also play a paramount role (Jakob and Hungr 2005; McDougall and Hungr 2005).

However, all the mentioned mechanisms are not yet definitively addressed and analysed in the scientific literature and some open issues still exist. Among the open issues, it is worth mentioning the geomechanical modelling for which few insights are currently furnished. Particularly, Cascini et al. (2008b) provide a preliminary contribution on the failure stage induced by impact loading and springs from bedrock inside pyroclastic shallow deposits of Southern Italy; Crosta et al. (2006) and Chen et al. (2006) address the erosion phenomena occurring inside the avalanche source areas; finally, Pastor et al. (2008a) provide pioneristic examples of numerical simulations of debris avalanches occurred in Hong Kong.

Considering the relevance of the topic, essentially related to the destructiveness of these phenomena, it is the authors' opinion that an advanced modelling of debris avalanches could provide a valuable tool to improve (i) our understanding of the inception (i.e. triggering mechanism and avalanche formation) of debris avalanches, (2) our capability to forecast these landslides and (3) the evaluation of the mobilised volume inside the avalanche source area, which is a crucial point for hazard and risk assessment and zoning. As a contribution to the topic, this paper proposes some general remarks also outlining different suitable approaches for modelling whose potentialities and limitations are tested for a relevant case study of Southern Italy. 


\section{Stages and zones of debris avalanches}

Two different stages can be individuated for debris avalanches, i.e. the failure stage and the avalanche formation stage: The former includes all the triggering mechanisms that cause the soil to fail; the latter is associated to the increase in the unstable volume. Referring to these stages, four different zones can be distinguished (Fig. 1). Zone 1 corresponds to small failures that occur at natural or anthropogenic discontinuities of soil deposits (respectively, bedrock outcrops and cut slopes). Zone 2 is the impact zone of the previously mentioned failed masses that usually corresponds to water supplies from bedrock (either karst spring or water runoff at bedrock outcrops); if zone 1 is absent, zone 2 is the source area of small landslides triggered by water supplies from bedrock. Zone 3 corresponds to distinct mechanisms: thrust of the failed mass upon the downslope stable material and/or soil entrainment due to the propagating mass. Zone 4 exclusively corresponds to soil entrainment. It is worth noting that while zones 1 and 2 are few tens of metres large, the width of zones 3 and 4 is not known a priori and its forecasting is a challenging task.

\section{Mechanics of debris avalanches}

Referring to the stages and zones in Fig. 1, the mechanics of debris avalanches can be well analysed referring to the scheme of infinite slope (Fig. 2 ) and to the stress invariants $q$ and $p^{\prime}$ defined as follows:

$\sigma^{\prime}=\sigma-p_{\mathrm{a}} I+S_{\mathrm{r}}\left(p_{\mathrm{a}}-p_{\mathrm{w}}\right) I$

$q=\frac{1}{\sqrt{2}} \sqrt{\left(\sigma_{1}^{\prime}-\sigma_{3}^{\prime}\right)^{2}+\left(\sigma_{1}^{\prime}-\sigma_{2}^{\prime}\right)^{2}+\left(\sigma_{2}^{\prime}-\sigma_{3}^{\prime}\right)^{2}}$

$p^{\prime}=\left(\sigma_{1}^{\prime}+\sigma_{2}^{\prime}+\sigma_{3}^{\prime}\right) / 3$ where $\sigma^{\prime}$ is the effective stress tensor, $\sigma$ is total stress tensor, $p_{\mathrm{a}}$ is the air pore pressure, $p_{w}$ is the pore water pressure, $s=p_{a}-p_{w}$ is the suction, $S_{\mathrm{r}}$ is the degree of saturation and $I$ is the identity tensor of second order.

Particularly, in situ initial conditions (before the debris avalanche has been triggered) at zones 2 and 3 of Fig. 1 depend on soil saturation degree $\left(S_{\mathrm{r}}\right)$ and are represented by the stress point $\mathrm{o}$ of Fig. 2. In dry condition $\left(S_{\mathrm{r}}=0\right)$ the principal stress directions $\left(\sigma_{i=1,2.3}^{\prime}\right)$ are known (Iverson et al. 1997; Lambe and Whitman 1979), and the normal stress values $\sigma_{z}^{\prime}, \sigma_{y}^{\prime}$ and $\sigma_{5}^{\prime}$ can be easily obtained if the lateral earth pressure coefficient $k_{\mathrm{o}}$ refers to stress conditions at rest (Jaky 1944). Particularly, $\sigma_{z}^{\prime}$ increases with soil depth while both $\sigma_{y}^{\prime}$ and $\sigma_{s}^{\prime}$ increase with slope angle. In the case of steep slopes, equilibrium conditions require high soil friction angles, which correspond to low values of $k_{\mathrm{o}}$ and $\sigma_{y}^{\prime}$; consequently, the associated $\left(p^{\prime}, q\right)$ points have a high stress ratio $\eta=q / p^{\prime}$, and they lie very close to the failure criterion. For saturated soil condition $\left(S_{\mathrm{r}}=1\right)$, the soil unit weight $\left(\gamma_{\text {sat }}\right)$ and the deviatoric stress $(q)$ are higher than in the previous case, while the mean effective stress $\left(p^{\prime}\right)$ can be either higher or lower, depending on soil unit weight $\left(\gamma_{\text {sat }}\right)$ and pore water pressure $\left(p_{w}\right)$. Therefore, for saturated soil condition $\left(S_{\mathrm{r}}=1\right)$, the $\left(p^{\prime}, q\right)$ stress points can be even closer to the failure line than for dry condition $\left(S_{\mathrm{r}}=0\right)$. For unsaturated soil condition $\left(S_{\mathrm{r}}<1\right)$, the suction $(s)$ determines higher mean effective stresses $\left(p^{\prime}\right)$ than in saturated condition and a shear strength envelope with a positive apparent cohesion intercept (Fredlund et al. 1978); thus, the stress points $\left(p^{\prime}, q\right)$ are more distant from the failure criterion than in saturated soil conditions.

When an impact loading occurs (see zone 2 of Fig. 1), it mainly corresponds to an increase of deviatoric stresses; the stress paths are inside the zone A of Fig. 2 (for drained conditions) or in the zone B of Fig. 2 (for undrained conditions). In the latter case, the stress path may rapidly approach the failure criterion. However, the assumption of drained or undrained conditions can be more

Fig. 1 A reference scheme for the inception and propagation of a debris avalanche. General features: a bedrock, $\mathrm{b}$ stable soil deposit, c failed soil, d propagating failed mass, e entrained material, $f$ boundary of debris avalanche and $\mathrm{g}$ propagation pattern. Triggering factors: I spring from bedrock, II impact loading. Zone 1-2 triggering; zone 3 thrust of failed material and/or soil entrainment; zone 4 soil entrainment, zone 5 propagation 
Fig. 2 Principal stresses for indefinite slope and different stress paths induced by a drained impact (zone A), b undrained impact (zone B), spring from bedrock (zone $C$ ), d liquefaction (zone $B$ and/or $C$ ) and e thrust of failed mass on stable soils (zone B or to be determined)
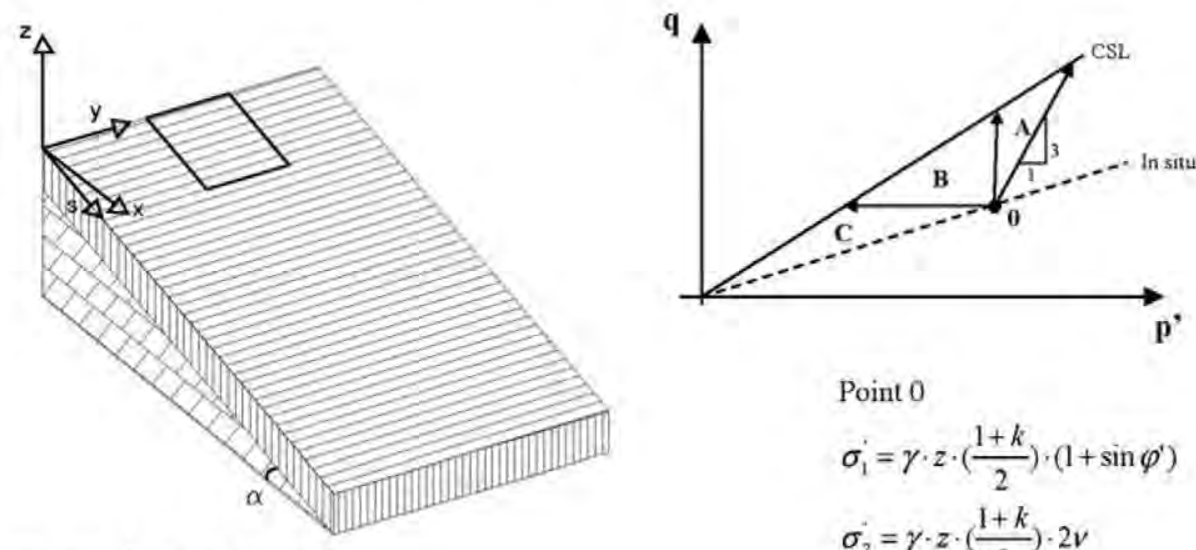

$$
\begin{aligned}
& \sigma_{i}^{\prime}=t_{v} \cdot k=\gamma \cdot z \cdot k \cdot \cos \alpha \\
& \sigma_{z}^{\prime}=\gamma \cdot z \cdot\left(1+k \cdot \sin ^{2} \alpha\right) \\
& \sigma_{x}^{\prime}=\gamma \cdot z \cdot k \cdot \cos ^{2} \alpha=\tau_{x y} \cdot \tan \alpha \\
& \sigma_{y}^{\prime}=\gamma \cdot z \cdot v \cdot(1+k) \\
& k_{0}=\sigma_{x}^{\prime} / \sigma_{z}^{\prime}=1-\sin \varphi^{\prime} \\
& k=k_{0} /\left(\cos ^{2} \alpha-k_{0} \sin ^{2} \alpha\right)
\end{aligned}
$$

Point 0

$$
\begin{aligned}
& \sigma_{1}^{\prime}=\gamma \cdot z \cdot\left(\frac{1+k}{2}\right) \cdot\left(1+\sin \varphi^{\prime}\right) \\
& \sigma_{2}=\gamma \cdot z \cdot\left(\frac{1+k}{2}\right) \cdot 2 v \\
& \sigma_{3}=\gamma \cdot z \cdot\left(\frac{1+k}{2}\right) \cdot\left(1-\sin \varphi^{\prime}\right)
\end{aligned}
$$

or less acceptable depending on loading velocity and soil conductivity and the hydro-mechanical coupling between the solid skeleton and pore fluid may play a crucial role, as discussed later. Other triggering factors such as direct rainfall infiltrating the slope ground surface, karst springs from bedrock or runoff from upslope bedrock outcrops induce stress paths in the zone $\mathrm{C}$ of the $q-p^{\prime}$ plot of Fig. 2 ; in these cases, fully drained conditions can be reasonably assumed (Cascini et al. 2010).

For the avalanche formation, remarks can be also outlined referring to the zone 3 of Fig. 1. Particularly, the occurrence of soil liquefaction is strongly related to the initial stress state in the $q-p^{\prime}$ plane (Fig. 2) and mechanical features of soils, thus corresponding to stress paths moving in the zone B and/or C of the $q-p^{\prime}$ plot of Fig. 2 . Analogously, the thrust of an unstable mass upon downslope stable soils cause an increase in deviatoric stresses and a stress path moving in the zone B of $q-p^{\prime}$ plot of Fig. 2. On the other hand, soil entrainment phenomena depends on the kinematic features of the propagating mass, which are, in turn, related to: (1) initial volume, (2) rheological behaviour and (3) hillslope topography.

\section{A unified mathematical framework for modelling}

Modelling the mechanisms of debris avalanches requires an enhanced mathematical framework able to capture the peculiar mechanical aspects of these phenomena, i.e. (1) small soil deformations up to failure while large soil deformations and even material entrainment during the avalanche formation, (2) relevance of the hydro-mechanical coupling between solid skeleton and pore fluid during the whole process.

This paper proposes the use of a unified mathematical framework, for both triggering and avalanche formation, which is based on the fundamental contributions of Biot $(1941,1955)$ and Zienkiewicz et al. (1999, 1980).

The most widely used form of Biot-Zienkiewicz equations is the so-called "displacement-pore pressure" model, which is obtained in the cases where fluid accelerations are small; details on this model are provided by Pastor et al. (2008b). Here, it is worth noting that the soil consists of a solid skeleton and two fluid phases, water and air, which fills the voids; total and effective stresses are defined by Eq. 1, and the fundamental equations of this framework consist in: (1) the balance of momentum equation for the mixture (Eq. 4), (2) a combination of balance of mass and momentum of the pore fluid (Eq. 5), (3) a kinematic relation linking velocities to rate of deformation tensor, and (4) a suitable constitutive or rheological equation.

$\operatorname{div}\left(\sigma^{\prime}-\bar{p} I\right)+\rho \mathbf{b}=\rho \frac{\mathrm{d}^{2} u}{\mathrm{~d} t^{2}}$

$$
\left(C_{\mathrm{s}}+\frac{1}{Q^{*}}\right) \frac{\mathrm{d} p_{\mathrm{w}}}{\mathrm{d} \ell}+S_{\mathrm{r}} \operatorname{div}\left(\frac{\mathrm{d} u}{\mathrm{~d} \ell}\right)-\operatorname{div}\left(k_{\mathrm{w}} \operatorname{grad} p_{\mathrm{w}}\right)=0
$$

where $\rho$ is the mixture density, $\mathbf{b}$ is the vector of body forces, $u$ is the displacement of soil skeleton, $\bar{p}=S_{r} p_{w}$ is the so-called averaged pore pressure and $n$ is the soil porosity (volumetric fraction of pores). Furthermore, $\left.\frac{1}{Q^{\prime}}=\frac{n S_{s}}{K_{w}}+\frac{1-n}{K_{s}}\left(S_{r}+p_{w} \frac{C_{s}}{n}\right)\right]$ and $C_{s}$ is the specific moisture capacity, $K_{\mathrm{s}}$ is the volumetric stiffness of soil particles and $K_{\mathrm{w}}$ is the volumetric stiffness of pore water.

The equations and unknowns are four and the analysis is based on displacements $(u)$ and pore pressures $\left(p_{w}\right)$, from where the name of the model comes.

From this mathematical framework, different modelling alternatives can be derived consisting in: (1) coupled stress-strain approach, (2) uncoupled stress-strain approach and (3) uncoupled limit equilibrium approach. The first approach consists of Eqs. 4 and 5 completed with a soil constitutive model (relating stress and strain tensors) and kinematic relation linking displacement to deformation tensor. The second approach uses the same equations in the hypothesis of negligible soil deformation rate, and thus, the modified versions of Eqs. 4 and 5 are uncoupled. Pore water pressures are computed first from Eq. 5 and then soil stresses from 
Eq. 4; finally, displacements and strains from kinematic and constitutive relations. In the third approach, the modified version of Eq. 5 is still used to compute pore water pressures; stresses and a slope safety factor are computed from an integral form of Eq. 4, while strains and displacements are not taken into account. Details on these approaches are provided in Cascini et al. (2010).

In this paper, a hydro-mechanical coupled finite element method (FEM) code named "GeHoMadrid" (Mira McWilliams 2002) will be used for the coupled stress-strain analyses; a commercial FEM code [SIGMA/W, (Geoslope 2004)] for uncoupled stress-strain analyses; and a commercial code [SLOPE/W, (Geoslope 2004)] for limit equilibrium analyses. It will be shown that all these approaches can be profitably used for modelling the failure stage of a debris avalanche (according to distinct triggering mechanisms) and some issues related to the avalanche formation.

From the Biot-Zienkiewicz model, it is also possible to derive a 3D "propagation-consolidation" model, where the velocity of soil skeleton and pore pressure are the unknown, and pore pressure dissipation takes place along the normal to the terrain surface. In this approach, it is assumed that the velocity of soil skeleton and pressure fields can be split into two components, i.e. propagation and consolidation as $v=v_{\mathrm{o}}+v_{\mathrm{l}}$ and $p_{\mathrm{w}}=p_{\mathrm{wo}}+p_{\mathrm{w} r}$. Since many flowlike landslides have average depths small in comparison with their length or width, the $3 \mathrm{D}$ propagation-consolidation model can be simplified by integrating its equations along the vertical axis. The resulting $2 \mathrm{D}$ depth integrated model presents an excellent combination of accuracy and simplicity providing important information such as velocity of propagation, time to reach a particular place, depth of the flow at a certain location, etc. Details on this model are provided by Pastor et al. (2009). In this paper a smoothed particle hydrodynamics (SPH) code named "GeoFlow_SPH" (Pastor et al. 2009) is used [in addition to a simple entrainment law proposed by Hungr (1995) to investigate the lateral spreading of the propagating mass during the avalanche formation stage.

\section{Case study}

\section{The May 1998 Sarno-Quindici debris avalanches}

In Campania region (Southern Italy), a large area $\left(1,400 \mathrm{~km}^{2}\right)$ is characterised by unsaturated coarse grained pyroclastic soil deposits, which overlie carbonate massifs (Cascini and Sorbino 2002). In this area, shallow landslides of the flow type have been systematically recorded for many centuries (Cascini et al. 2005; Cascini et al. 2000; Guadagno et al. 2005) and a very destructive event occurred on 4-5 May 1998. Particularly, at Pizzo d'Alvano massif $\left(60 \mathrm{~km}^{2}\right)$, heavy rainfall triggered tens of catastrophic landslides of the flow type (Cascini et al. 2000; Fiorillo and Wilson 2004), thus causing 159 fatalities and relevant damage to properties. For these landslides, six different triggering mechanisms are recognised by Cascini et al. (2008a; Cuomo 2006), among which two different mechanisms for debris avalanches: (1) the mechanism M2a, related to karst springs from the bedrock, and (2) the mechanism $\mathrm{M}_{2} \mathrm{~b}$, associated to the impact of failed soil masses on stable deposits. Particularly, karst springs were active for periods shorter than $24 \mathrm{~h}$ with discharge lower than $10^{-4} \mathrm{~m}^{3} / \mathrm{s}$, and impact phenomena were related to small volumes of failed soil masses $\left(10-100 \mathrm{~m}^{3}\right)$ falling from bedrock outcrops $(2-20 \mathrm{~m} \mathrm{high})$. A schematic view of the triggering mechanisms $M_{2} a$ and $M_{2} b$ is provided in Fig. 3, which also shows the spatial distribution of the May 1998 debris avalanches. Figure 4 shows two typical
Fig. 3 Debris avalanches (M2) occurred in the study area on May 1998

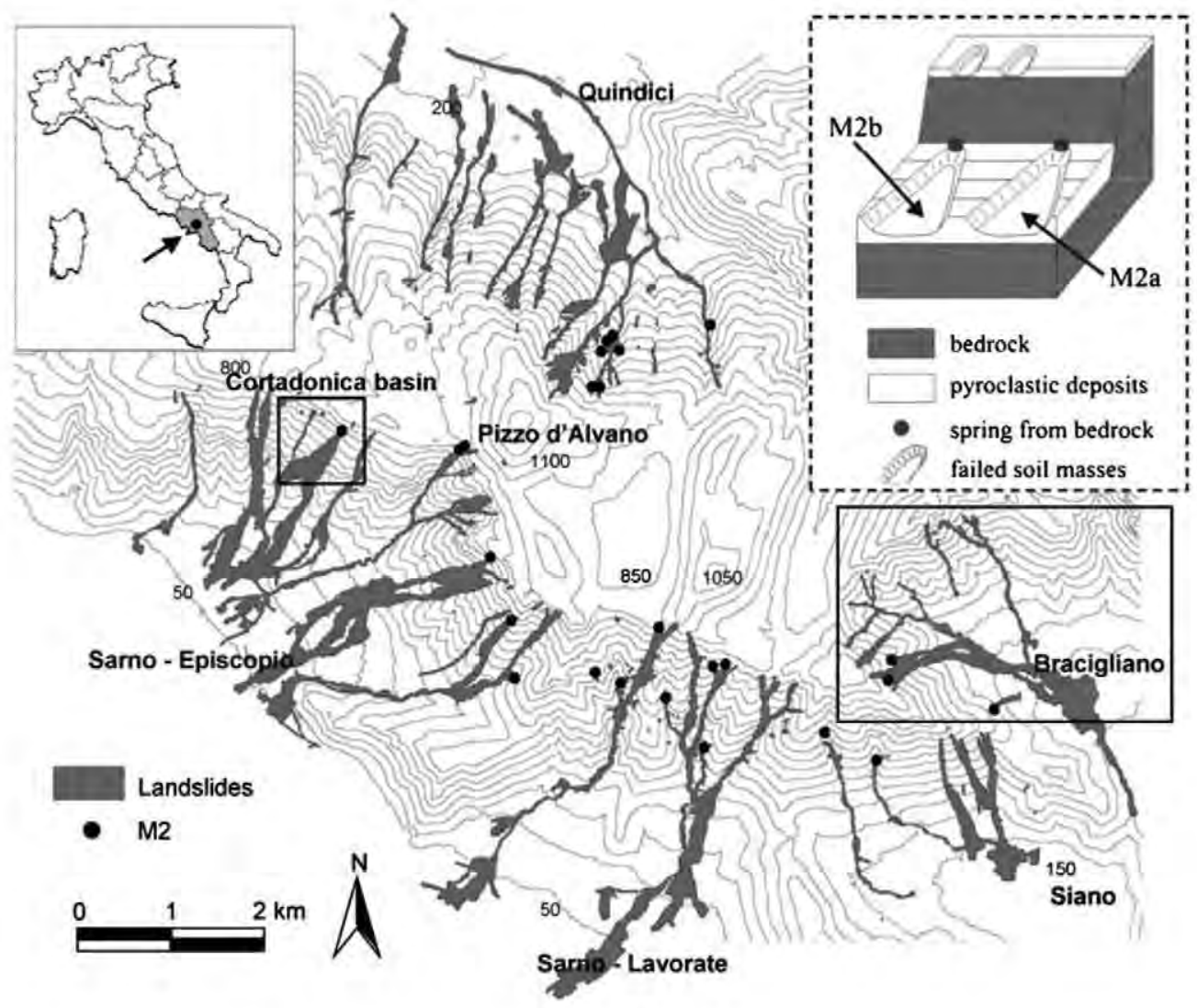




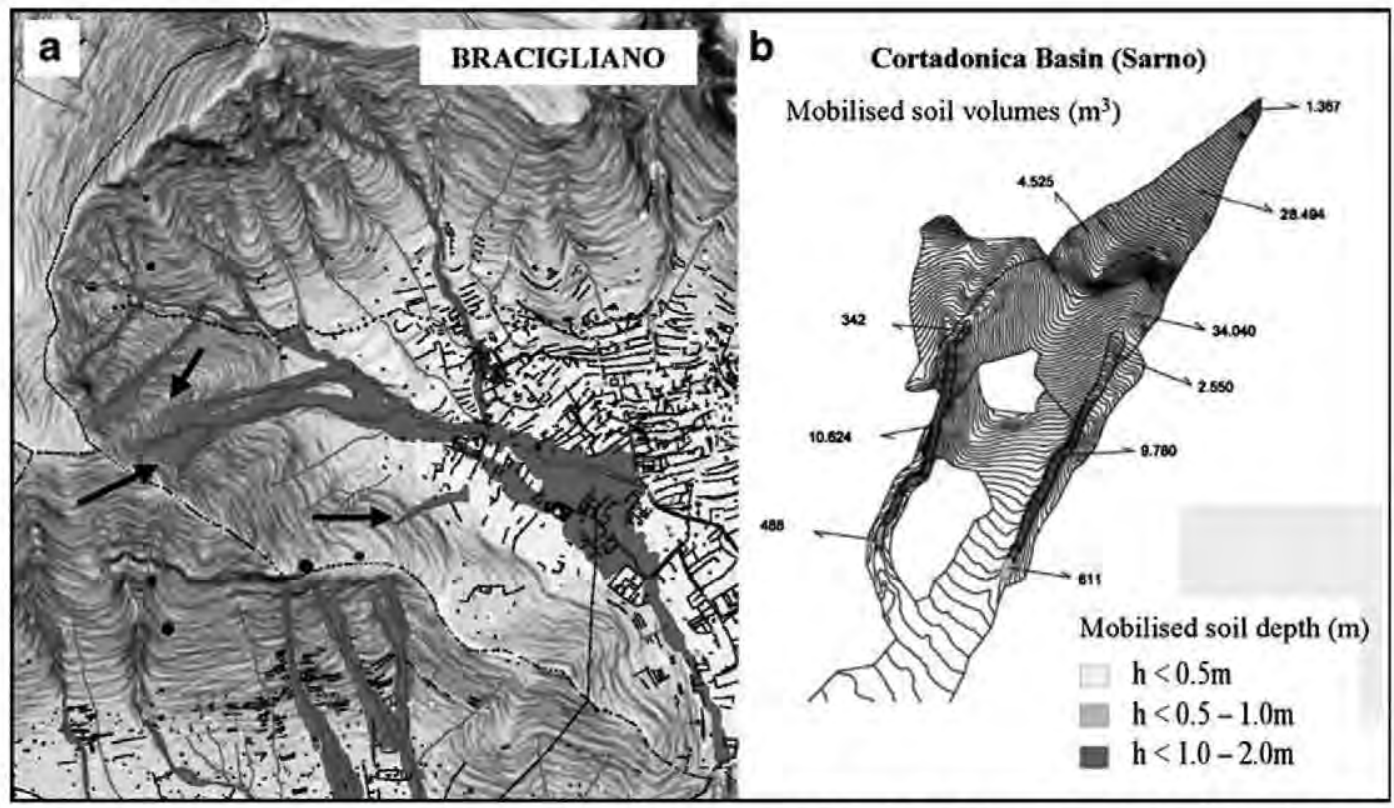

Fig. 4 Examples of debris avalanches triggered by the mechanism M2a in the Bracigliano sector (a) and by the triggering mechanism M2b in the Cortadonica basin, Sarno sector (b) [data from Cascini (2004)]

examples of debris avalanches triggered by the aforementioned mechanisms in Bracigliano (mechanism M2a, see Fig. 4a) and in the Cortadonica basin (mechanism M2b, see Fig. 4b).

Considering the relevance of the occurred phenomena, several authors investigated the 1998 event, and some contributions are devoted to the analysis and/or modelling of debris avalanches. Particularly, Guadagno et al. (2003) highlight the role of bedrock scarps in causing upslope small failures, i.e. this contribution refers to zone 1 of sketch of Fig. 1; however, it is not demonstrated that these failures are then capable to induce large debris avalanches (in the zone 2 of Fig. 1). Calcaterra et al. (2004) show that karst springs from bedrock may affect the groundwater regime in large portions of the pyroclastic deposits $(2-12 \mathrm{~m}$ in length) after $6-24$ h, i.e. this paper refers to the zone 2 of Fig. 1; however, slope stability analyses are not provided. Di Crescenzo and Santo (2005) characterise the geometrical features of sources areas, and they indicate apex angles mostly in the range of $15^{\circ}-30^{\circ}$, i.e. they refer to the zone 3 and 4 of Fig. 1, but it is not proposed a physically based interpretation of this field evidence. Finally, referring to these zones, Guadagno et al. (2005) propose morphometrical analyses of the main geometrical features of the landslides source areas, such as apex angle of the source areas, height of natural and anthropogenic scarps, slope length, slope angle and initial volume; however, these factors are poorly correlated each other, probably due to the analysis of different undistinguished mechanisms.

In conclusion, the analysis of the literature reinforces the stages and zones proposed in Fig. 1; at the same time, it is highlighted that analyses and modelling of the 1998 debris avalanches have not been sufficiently addressed, and further issues should be investigated. For this reason, in the following sections the geomechanical modelling is on the basis of the proposed mathematical framework and the available dataset hereafter summarised.

\section{Geomechanical dataset}

The dataset includes information concerning both in situ conditions and soil properties. As for the in situ conditions, it is observed that open slopes are generally steep $\left(30^{\circ}-40^{\circ}\right)$ with shallow soil deposits (thickness up to $4.5 \mathrm{~m}$, typically lower than $2.5 \mathrm{~m}$ ). Stratigraphy consists of alternating layers (0.2-2 $\mathrm{m}$ thick) of three main soil classes, i.e. pumice soils, coarser superficial ashy soils (class B) and finer deep ashy soil (class A) (Fig. 5). Typical values of pore water pressures are also known, being the measured suction ranging from $5 \mathrm{kPa}$ (in March-May and DecemberFebruary periods) up to $65 \mathrm{kPa}$ (from June to November) (Cascini and Sorbino 2002; Sorbino 2005). However, groundwater modelling of the May 1998 event outlines that the suction possibly reduces up to null values due to rainfall infiltration and karst springs from the bedrock (Cascini et al. 2003).

As for the soil mechanical properties in saturated and unsaturated conditions (Fig. 6, Table 1), the literature provides the soil water content and conductivity curves as well as the shear strength and stiffness for the above-mentioned suction values (Bilotta et al. 2005), which are here used for numerical analyses. For details on laboratory investigations, Bilotta et al. (2005) can be referred.

Geomechanical modelling of triggering mechanisms

\section{Modelling of failure induced by karst springs}

The first numerical analyses refer to a $4.5-\mathrm{m}$ thick soil deposit (with different stratigraphies of Fig. 6 and $30^{\circ}$ slope angle), subjected to the 4-5 May 1998 rainfall and a karst spring from the

\section{schemes}

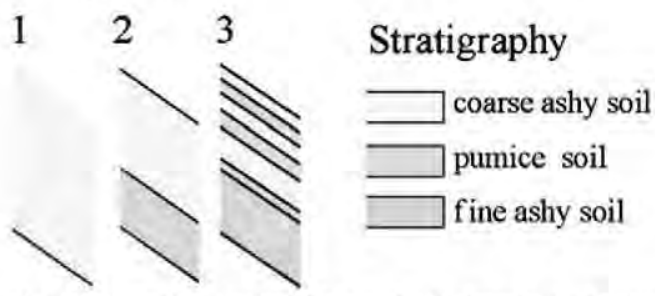

Fig. 5 Typical stratigraphical sections for pyroclastic deposits in the study area 

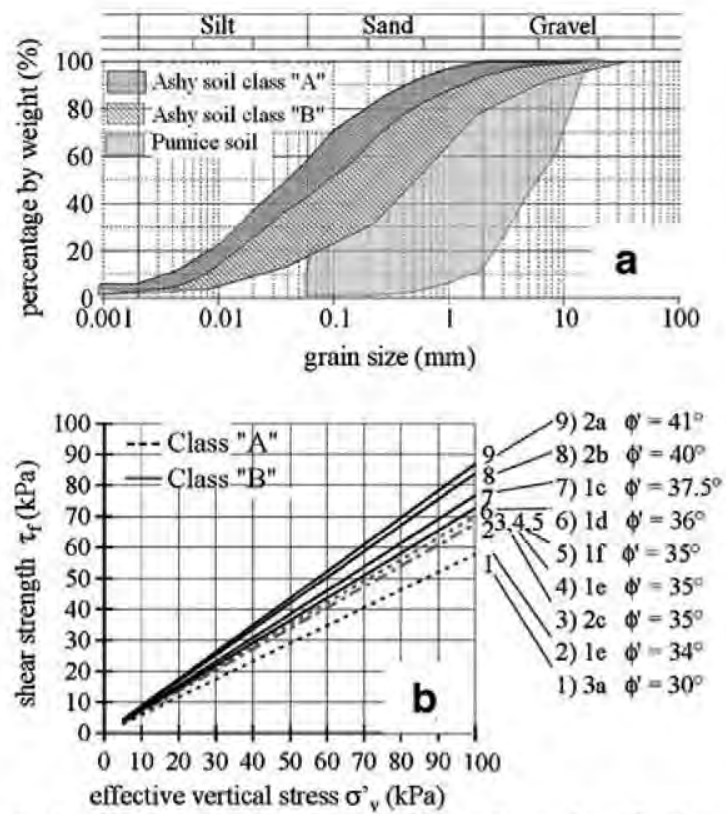
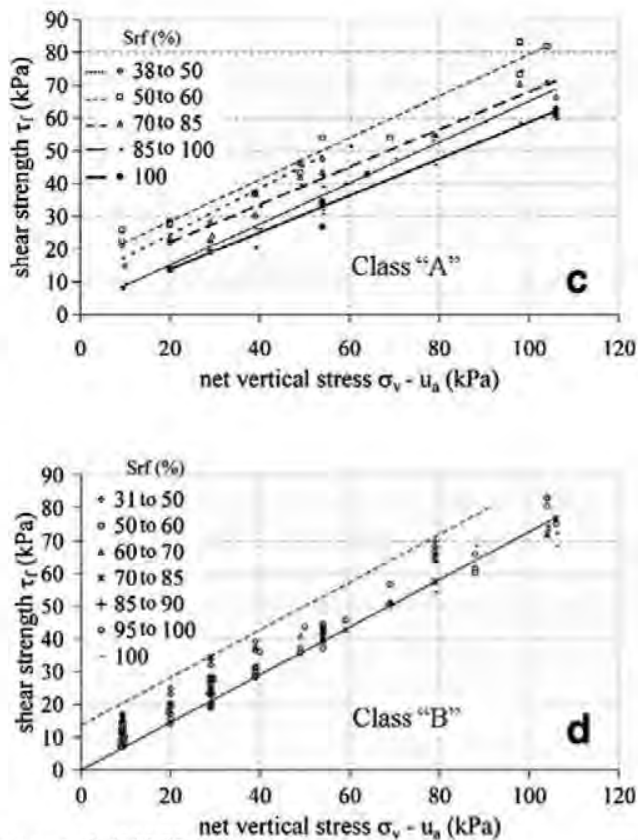

Fig. 6 Main mechanical features of pyroclastic soils in the study area [modified from Bilotta et al. (2005)]

bedrock. A transient seepage analysis is carried out for the period January 1, 1998-May 3, 1998 through the Seep/W Finite Element code (Geoslope 2004) to evaluate the pore water pressures at the beginning of May 4 th. To this aim, the soil water characteristic curves of Cascini et al. (2003) are used and rainfall data provided by Cascini et al. (2005). Unsaturated soil conditions are simulated on May 4th, 1998 for each scheme of Fig, 6. The effects of rainfall and karst spring from bedrock are evaluated for the period 4-5 May with the following boundary conditions: (1) the rainfall values indicated by Cascini et al. (2008b) at the ground surface; (2) an impervious contact between bedrock and pyroclastic deposits; (3) a water flux (karst spring) with discharges $(Q)$ ranging from $10^{-5}$ to $10^{-4} \mathrm{~m}^{3} / \mathrm{s}$ at the left lateral boundary of the pyroclastic deposits; (4) alternatively to point 3 , a hydrostatic pore water pressures distribution are also considered, to reproduce the filling of fractures, which are quite common at the uppermost portion of the open slopes.

The performed analyses show that a karst spring induces transient positive pore water pressures (Fig. 7) equal to 30 and $40 \mathrm{kPa}$, as maximum, respectively, for schemes 1 and 2. A similar effect is caused by a hydrostatic distribution of pore water pressures at the upper boundary of pyroclastic deposits. The numerical results also outline that stratigraphy is a key factor for groundwater regime since (1) the presence of ashy A soils strongly increase the simulated pore water pressures (scheme 2) and (2) continuous pumice soil layers (scheme 3 ) empathies the role of kasrt spring and a high increase of pore water pressures is simulated. These results are in agreement with those proposed by Calcaterra et al. (2004) while referring to a more general list of analysed cases.

The triggering mechanism M2a is investigated via limit equilibrium analyses by using either the methods of Janbu (1954) or Morgenstern and Price (1965), through the Slope/W code (Geoslope 2004). A large number of planar and curvilinear slip surfaces are considered to investigate both the shape and location of the slip surface associated to the minimum factor of safety (FS). The latter corresponds to slightly curvilinear slip surfaces, which are located at different depths depending on the considered stratigraphy (Fig. 7). Failure conditions are simulated assuming low discharges $\left(3 \times 10^{-5} \mathrm{~m}^{3} / \mathrm{s}\right)$ over a short time period $(20 \mathrm{~h})$. Failed volumes vary from 200 to $500 \mathrm{~m}^{3}$, depending on either pore water pressures or shear strength properties, which, in turn, are both related to stratigraphy; the latter is confirmed as a key factor for landsliding.

The mechanism M2a is also analysed via stress-strain analyses, developed through the FEM Sigma/W code (Geoslope 2004). As initial stresses, the formation of the soil deposit is simulated by the construction of multiple layers $0.4 \mathrm{~m}$ thick each, as suggested by Cascini et al. (2010). As input data for the analyses, the transient pore water pressures previously computed over the period 4-5 May are considered to simulate the evolution in time of stresses and strains. As for the mechanical properties, a simple elastic-perfectly plastic constitutive model is considered with the soil mechanical properties of Table 1.

Table 1 Physical and mechanical properties of pyroclastic soils (Bilotta et al. 2005)

\begin{tabular}{|lcccccccccc|}
\hline & $\gamma_{d}\left(\mathrm{kN} / \mathrm{m}^{3}\right)$ & $\gamma_{\text {sat }}\left(\mathrm{kN} / \mathrm{m}^{3}\right)$ & $n$ & $k_{\text {sat }}(\mathrm{m} / \mathrm{s})$ & $c^{\prime}(\mathrm{kPa})$ & $\varphi^{\prime}\left({ }^{\circ}\right)$ & $\varphi^{\mathrm{b}^{\mathrm{b}}\left({ }^{\circ}\right)}$ & $n$ & $E(\mathrm{kPa})$ & $\Psi\left(^{(}\right)$ \\
\hline Ashy soils (class A) & 9.10 & 15.7 & 0.66 & $10^{-6}$ & $5 \div 15$ & $32 \div 35$ & 20 & 0.29 & $3000 \div 7000$ & $0 \div 20$ \\
\hline Pumice soils & 6.20 & 13.1 & 0.69 & $10^{-4}$ & 0 & 37 & 20 & - & - & - \\
\hline Ashy soils (class B) & 7.30 & 13.1 & 0.58 & $10^{-5}$ & $0 \div 5$ & $36 \div 41$ & 20 & 0.29 & $3000 \div 7000$ & $0 \div 20$ \\
\hline
\end{tabular}

$\gamma_{d}$ dry unit weight, $\gamma_{\text {sat }}$ saturated unit weight, $n$ porosity, $k_{\text {sat }}$ saturated hydraulic conductivity, $c^{\prime}$ effective cohesion, $\varphi^{\prime}$ friction angle, $\varphi^{b}$ rate of increase in shear strength due to suction [according to the failure criterion of Fredlund et al. (1978)] $\nu$ Poisson ratio, $E$ Young modulus, $\psi$ dilatancy angle 
Fig. 7 Failure stage induced by karst springs from bedrock: a pore water pressures simulated at failure, $\mathbf{b}$ slope factor of safety (FS) versus time as computed through limit equilibrium analyses and $c$ displacements at vertical passing for point $P$ as simulated via uncoupled stress-strain analyses
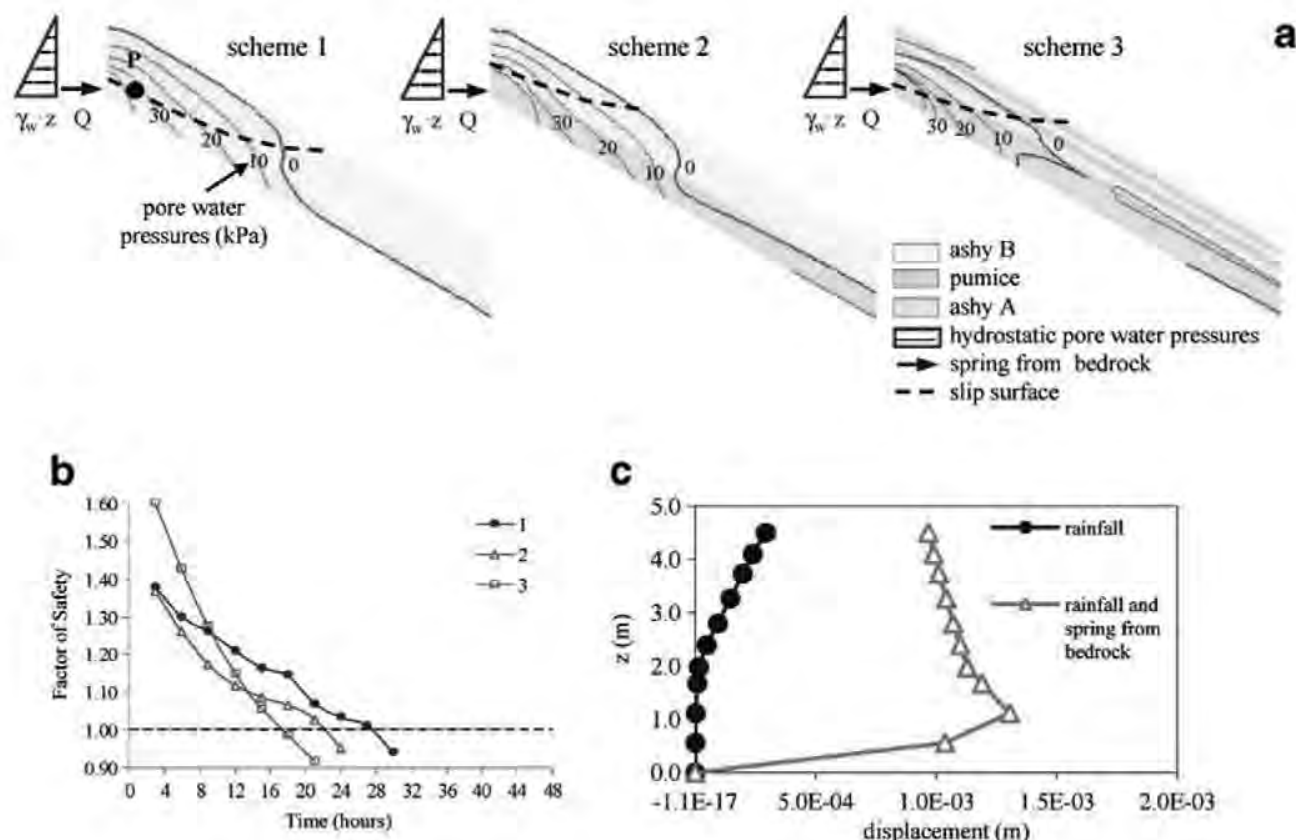

C

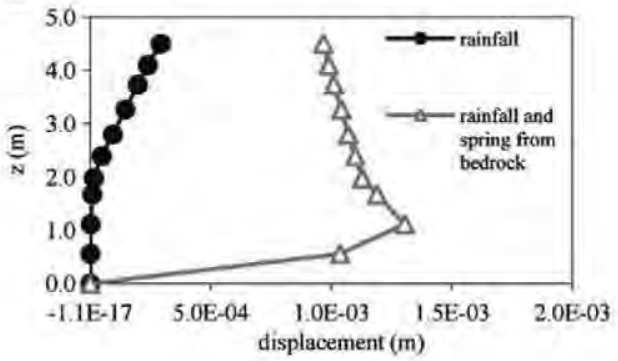

In all the considered schemes, limit equilibrium and stressstrain analyses provide analogous results. For instance, for scheme 1 , the maximum simulated displacements concentrate almost at the bedrock-cover contact (see solid line with triangles in Fig. $7 \mathrm{c}$ ) well matching the slip surface in the limit equilibrium analyses (Fig. $7 \mathrm{a}$ ). Globally, the achieved results outline the spring from bedrock as a crucial factor for failure onset in agreement with literature; moreover, insights are provided on the mobilized volumes and role of stratigraphy of soil deposits.

\section{Modelling of failure induced by the impact of an unstable mass}

The modelling of the impact-related mechanism ( $\mathrm{M}_{2} \mathrm{~b}$ ) poses important challenges with reference to the assessment of both impact forces (loading geometry) and impact conditions (drained, undrained or fully coupled hydro-mechanical conditions).

In this paper, different sizes of the impact zone are hypothesised (not larger than $15 \mathrm{~m}$ ). The loading pressures are assumed vertical and uniform in the impact zone. Their values are estimated through the procedure proposed by Wang et al, (2003) based on energy conservation; thus, values ranging between 5 and $30 \mathrm{kN} / \mathrm{m}$ are obtained. For the impact loading, duration times are assumed equal to 1-10 s, and inertial forces are not taken into account in the performed analyses. As for the water drainage conditions, different hypotheses are assumed, as later discussed.

Limit equilibrium analyses are carried out referring to the slope schemes of Fig. 5, considering drained conditions and assuming as input data distinct pore water pressures: (1) equal to those obtained on 4 th May 1998 in the previous section and (2) uniform suction values equal to $5-60 \mathrm{kPa}$. Several curvilinear and planar slip surfaces are assumed for computing the factor of safety through the methods proposed by Janbu (1954) or Morgenstern and Price (1965). The minimum factors of safety (FS) are obtained for planar slip surfaces with minor differences in slope angles and depth; this is found independently from: (1) stratigraphy, (2) pore water pressure and (3) impact loading pressure. Figure 8 shows the results obtained for different loading pressures and stratigraphies with a suction value assumed equal to $5 \mathrm{kPa}$. It is shown that the computed factors of safety are always higher than unity. Particularly, FS slightly increases at load application due to both slope geometry and loading conditions; then, FS achieves the initial value at load removal.

Drained stress-strain analyses have been also carried out through the Sigma/W code (Geoslope 2004), assuming the mechanical soil parameter of Table 1. However, these analyses do not allow simulating the failure onset, independently from the initial pore water pressure distribution or stratigraphy. From the results of both limit equilibrium and stress-strain analyses, it can be concluded that a drained condition is a not realistic assumption for mechanism M2b. This statement confirms previous contributions, which refer to "undrained loading" (Sassa 1985, among others) as principal mechanism related to the impact. In other words, during the impact loading, an increase in pore water pressures arise, which lead to the failure onset.

Aimed to take into account the hydro-mechanical coupling between solid skeleton and pore water, coupled stress-strain analyses are carried out through the GeHoMadrid code (Mira McWilliams 2002)

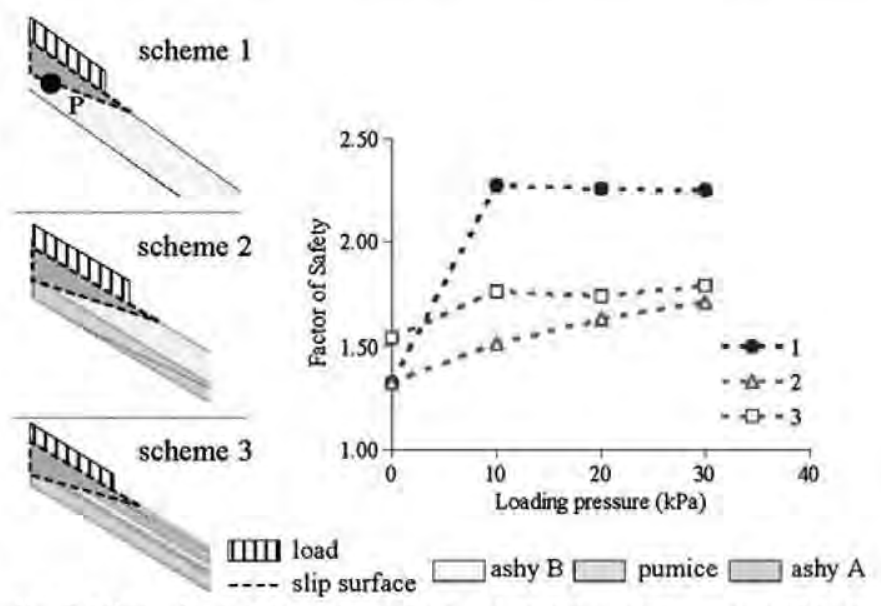

Fig. 8 Effects of a drained loading impact evaluated through the uncoupled limit equilibrium analyses 

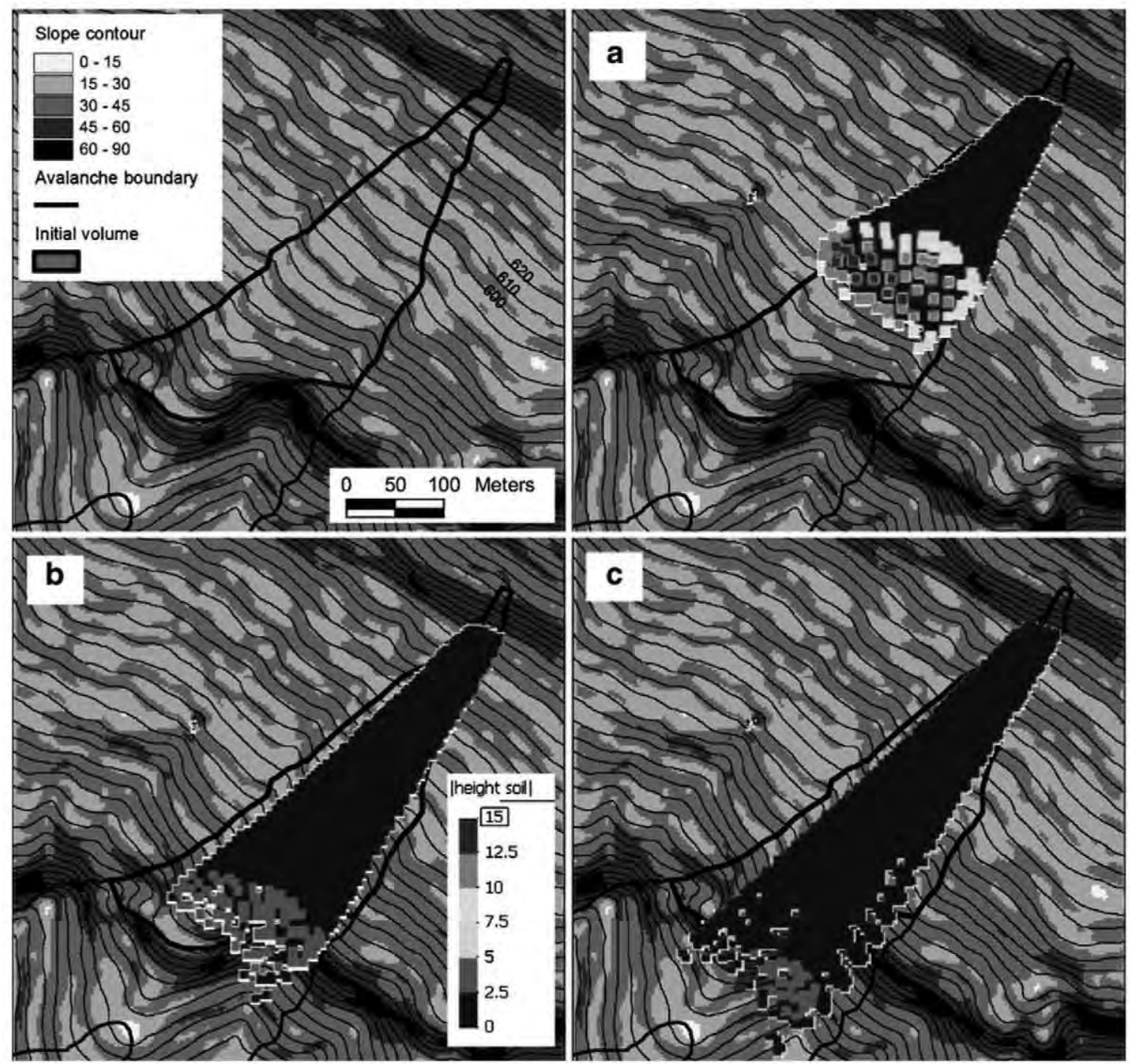

Fig. 11 Topography, initial volume and boundary of observed avalanche source area in the Cortadonica basin (Fig. 4b); Simulated heights of propagating mass with increasing rate of entrainment $(\mathbf{a} 0.0082, \mathrm{~b} 0.0012$ and $\mathrm{c} 0.0001)$ after the same elapsed time $(t=16 \mathrm{~s})$

Pastor et al. (2009) who back-analyse an important channelised landslide occurred during the May 1998 event (Table 2). The entrainment rate of the propagating mass is evaluated referring to the empirical model of Hungr (1995), which is based on morphometric features of landslides parameters, such as (1) initial and final volume and (2) travelled distance while erosion occurs. Thus, the computed erosion factor $E$ (often called spatial growth rate) is evaluated equal to $0.0084 \mathrm{~m}^{-1}$; however, also different values are considered for a parametric analysis (Table 2 ).
The achieved results show that the soil entrainment strongly influences the kinematic features of the propagating mass in the avalanche source area: (1) velocity is reduced by entrainment of material along the path, as evidenced by the distances simulated at the same time (after16s) for three different scenarios (a-c in Fig. 11), (2) propagation direction is also affected by soil entrainment (scenario "a" compared to scenario " $\mathrm{c}$ " of Fig. 11) and (3) lateral spreading of unstable mass is strongly favoured by entrainment phenomena. In the specific case study, it is furthermore evidenced that erosion

Table 2 Rheological and erosion parameters used for the analysis of propagation

\begin{tabular}{|c|c|c|c|c|c|c|c|c|c|}
\hline Case & $\tan \varphi^{\prime}$ & $B_{\text {fact }}\left(\mathrm{m}^{2} / \mathrm{s}\right)$ & $p_{w}{ }^{\text {rel }}$ & $h_{\mathrm{w}}{ }^{\text {rel }}$ & $D(\mathrm{~m})$ & $V_{0}\left(m^{3}\right)$ & $V_{f}\left(m^{3}\right)$ & $V_{\mathrm{f}} / V_{0}$ & $E\left(m^{-1}\right)$ \\
\hline 1 & & & & & & & 28,842 & 21.10 & 0.0084 \\
\hline 2 & 0.4 & 0.011 & 1.0 & 0.25 & 363 & 1367 & 2,113 & 1.55 & 0.0012 \\
\hline 3 & & & & & & & 1,428 & 1.04 & 0.0001 \\
\hline
\end{tabular}

$\varphi^{\prime}$ friction angle, $B_{\text {fact }}$ consolidation factor, $p_{w}{ }^{\text {rel }}$ maximum excess pore water pressure at the basal surface; $h_{\mathrm{w}}{ }^{\text {rel }}$ relative width of the basal saturated layer to the total depth, $D$ length of the inception zone, $V_{\mathrm{o}}$ initial volume, $V_{\mathrm{f}}$ final volume, $E$ erosion factor 
occurs especially in the uppermost portion of avalanche source area, while reducing in the lower portions of the hillslope. This can be argued from scenario "a" of Fig. 11, which provides a lateral spreading of the unstable mass matching the in situ evidences; further entrainment of material would have produced a wider avalanche area than the observed one. These results are in agreement with previous contributions (McDougall and Hungr 2005, among others), which outline the entrainment phenomena to be more intense in peculiar zones of the hillslope; in this case, it is highlighted that entrainment phenomena were more intense in the uppermost portion of the landslide source area.

\section{Concluding remarks}

Debris avalanches are complex natural hazard for which several field evidences or qualitative interpretations are provided in the current literature; conversely, few experimental laboratory tests are available and rare examples of geomechanical modelling can be found for this type of phenomena.

As a contribution to the topic, the paper firstly outlines stages, zones and features of debris avalanches. Then, for their analysis, the adoption of a unique mathematical framework is suggested from which different modelling approaches can be derived based on limit equilibrium method, FEM or smooth particle hydrodynamics (SPH). Lastly, the potentialities and limitations of the above approaches are tested for a case study where major debris avalanches affected shallow deposits of pyroclastic soils.

For the analysed case study, LEM analyses as well as uncoupled and coupled stress-strain FEM well simulate the two triggering mechanisms related to: (1) springs from bedrock and (2) impact of an unstable mass. In details, spring from bedrock lead to failure also for low water discharges and the simulated unstable volumes $\left(500 \mathrm{~m}^{3}\right.$ as a maximum) depend on stratigraphy. Due to the impact of an unstable mass, greater volumes (up to $1,400 \mathrm{~m}^{3}$ ) can be mobilized due to the increase in pore water pressures, as simulated in $2 \mathrm{D}$ and 3D hydro-mechanical coupled analyses.

As for the avalanche formation, the numerical results highlight that the presence of a soil mass, triggered by one of the previous mechanisms, can mobilise and entrain volumes moving downslope, especially in steep open slopes. The entrainment of material along the landslide path play an important role as it is evidenced by the coupled SPH analyses; particularly, entrainment causes the later spreading of the unstable mass and it also modifies the kinematic features, i.e. velocity and propagation patterns, of the debris avalanche in the source area.

In conclusion, the obtained results reinforce the key factors and mechanisms of debris avalanches outlined in this paper, thus encouraging the application of the proposed framework to further real cases to enhance the current capability to forecast the inception of these dangerous phenomena.

\section{References}

Bilotta E, Cascini L, Foresta V, Sorbino G (2005) Geotechnical characterization of pyroclastic soils involved in huge flowslides. Geotech Geol Eng 23:365-402

Biot MA (1941) General theory of three-dimensional consolidation. J Appl Phys 12: $155-164$
Biot MA (1955) Theory of elasticity and consolidation for a porous anisotropic solid. J Appl Phys 26:182-185

Budetta P, de Riso R (2004) The mobility of some debris flows in pyroclastic deposits of the northwestern Campanian region (Southern Italy). Bull Eng Geol Environ 63: 293-302

Calcaterra D, de Riso R, Evangelista A, Nicotera MV, Santo A, Scotto di Santolo A (2004) Slope instabilities in the pyroclastic deposits of the carbonate Appenine and the Phlegrean district (Campania, Italy). Proc. of the Int. Workshop "Flows 2003", Sorrento, Patron Ed., pp 61-75

Cascini L (2004) The flowslides of May 1998 in the Campania region, Italy: the scientific emergency management. Ital Geotech J 2:11-44

Cascini L, Sorbino G (2002) Soil suction measurement over large areas: a case study. Proc, 3rd International Conference on Unsaturated Soils, Recife (Brasil), Balkema, vol 2, pp 829-834

Cascini L, Guida D, Nocera N, Romanzi G, Sorbino G (2000) A preliminary model for the landslides of May 1998 in Campania Region. Proc 2nd Int. Symposium on Geotechnics of Hard Soil-Soft Rock-Napoli, Balkema, vol 3, pp 1623-1649

Cascini L, Sorbino G, Cuomo 5 (2003) Modelling of flowslides triggering in pyroclastic soils. Proc. Int. Conference on "Fast Slope Movements-Prediction and Prevention for Risk Mitigation", Napoli, Patron Ed., vol 1, pp 93-100

Cascini L, Cuomo S, Sorbino G (2005) Flow-like mass movements in pyroclastic soils: remarks on the modelling of triggering mechanisms. Ital Geotech I 4: $11-31$

Cascini L, Cuomo S, Guida D (2008a) Typical source areas of May 1998 flow-like mass movements in the Campania region, Southern Italy. Eng Geol 96:107125

Cascini L, Cuomo S, Pastor M, Fernández-Merodo JA (2008) Geomechanical modelling of triggering mechanisms for rainfall-induced triangular shallow landslides of the flowtype. In: Sànchez-Marrè M, Béjar J, Comas J, Rizzoli AE, Guariso G (eds) Proceedings of the iEMSs Fourth Biennial Meeting: International Congress on Environmental Modelling and Software (iEMSs 2008). 7-10 July 2008, Barcelona, Spain. International Environmental Modelling and Software Society (iEMSs), Manno, pp $1516-1523$

Cascini L, Cuomo S, Pastor M, Sorbino G (2010) Modelling of rainfall-induced shallow landslides of the flow-type. J Geotechn Geoenviron Eng ASCE 136(1):85-98

Chen H, Crosta GB, Lee CF (2006) Erosional effects on runout of fast landslides, debris flows and avalanches: a numerical investigation. Geotechnique 56(5):305-322

Costa JE, Williams GP (1984) Debris-flow dynamics (video tape). US Geological Survey, Open-File Report 84-606

Crosta G, Imposimato S, Roddeman DG (2006) Continuum numerical modelling of flowlike landslides. In: Evans et al. (eds.) Landslides from massive rock slope failure. Springer, Berlin, pp 211-232

Cruden DM, Varnes DJ (1996) Landslide types and processes. In: Turner AK, Schster RL (eds) Landslides investigation and mitigation. Transp. Res. Board Spec. Rep. 247, National Research Council, National Acamedy Press, Washington, pp 36-75

Cuomo S (2006) Geomechanical modelling of triggering mechanisms for flow-like mass movements in pyrodastic soils. PhD dissertation at the University of Salerno, Italy, p. 274

Daerr A, Douady 5 (1999) Two types of avalanche behaviour in granular media. Nature 399:241-243

Di Crescenzo G, Santo A (2005) Debris slides-rapid earth flows in the carbonate massifs of the Campania region (Southern Italy): morphological and morphometric data for evaluating triggering susceptibility. Geomorphology 66:255-276

Fiorillo F, Wilson RC (2004) Rainfall induced debris flows in pyroclastic deposits, Campania (Southern Italy). Eng Geol 75:263-289

Fredlund DG, Morgenstern NR, Widger RA (1978) The shear strength of unsaturated soils. Can Geotech J 15:313-321

Geoslope (2004) User's guide. GeoStudio 2004, Version 6.13. Geo-Slope, Calgary

Guadagno FM, Martino S, Scarascia Mugnozza G (2003) Influence of man-made cuts on the stability of pyroclastic covers (Campania-Southern Italy): a numerical modelling approach. Environ Geol 43:371-384

Guadagno FM, Forte R, Revellino P, Fiorillo F, Focareta M (2005) Some aspects of the initiation of debris avalanches in the Campania Region: the role of morphological slope discontinuities and the development of failure. Geomorphology $66: 237-254$

Hungr 0 (1995) A model for the runout analysis of rapid flow slides, debris flows and avalanches. Can Geotech J 32:610-623

Hungr O, Evans SG, Bovis MJ, Hutchinson JN (2001) A review of the classification of landslides of the flow type. Environ Eng Geosci VII(3):221-238 
Hungr O, McDougall S, Wise M, Cullen M (2008) Magnitude-frequency relationships of debris flows and debris avalanches in relation to slope relief. Geomorphology 96 : 355-365

Hutchinson $\mathrm{JN}_{i}$ Bhandari RK (1971) Undrained loading, a fundamental mechanism of mudflow and other mass movements. Geotechnique 21(4):353-358

Iverson RM, Reid ME, LaHusen RG (1997) Debris-flow mobilization from landslides. Ann Rev Earth Planet Sci 25:85-138

Jakob M, Hungr 0 (2005) Debris-flow hazard and related phenomena. Springer, Berlin Jaky J (1944) The coefficient of earth pressure at rest. J Soc Hung Eng Arch 78:355-358 Jamiesion B, Stethem C (2002) Snow avalanche hazards and management in Canada: challenges and progress. Nat Hazard 26:35-53

Janbu N (1954) Application of composite slip surface for stability analysis. In Proceedings of the European Conference on Stability of Earth Slopes, Stockholm, vol 3, pp 43-49 Lambe TW, Whitman RV (1979) Soil mechanics. Wiley, York, p 553

McDougall S, Hungr O (2005) Dynamic modelling of entrainment in rapid landslides. Can Geotech J 42:1437-1448

Mira McWilliams P (2002) Análisis por Elementos Finitos de Problemas de Rotura en Geomateriales. Ph.D. thesis, Escuela Técnica Superior de Ingenieros de Caminos, Canales y Puertos, Universidad Politécnica de Madrid

Morgenstern NR, Price VE (1965) The analysis of the stability of general slip surfaces. Geotechnique 15:79-93

Pastor M, Blanc T, Pastor MJ, Sánchez M, Haddad B, Mira P, Fernández-Merodo JA, Herreros MI, Drempetic V (2008) A SPH depth integrated model with pore pressure coupling for fast landslides and related phenomena. In: Ho K, Li V (eds) The 2007 International Forum on Landslide Disaster Management, Geotechnical Eng. Division, The Hong Kong Institution of Engineers, Hong Kong, pp 987-1014

Pastor M, Fernández Merodo JA, Herreros I, Mira P, González E, Haddad B, Quecedo M, Tonni L, Drempetic V (2008b) Mathematical, constitutive and numerical modelling of catastrophic landslides and related phenomena. Rock Mech Rock Eng 41:85-132

Pastor M, Haddad B, Sorbino G, Cuomo S, Drempetic V (2009) A depth integrated coupled SPH model for flow-like landslides and related phenomena. Int J Numer Anal Methods Geomech 33(2):143-172
Picarelli L, Olivares L, Comegna L, Damiano E (2008) Mechanical aspects of flow-like movements in granular and fine grained soils. Rock Mech Rock Eng 41(1):179-197

Revellino P, Hungr 0, Guadagno FM, Evans SG (2004) Velocity and runout prediction of destructive debris flows and debris avalanches in pyroclastic deposits, Campania region, Italy. Environ Geol 45:295-311

Sassa K (1985) The mechanism of debris flows. Proceedings, XI International Conference on Soil Mechanics and Foundation Engineering, San Francisco, vol 1, pp 1173-1176

Savage SB, Hutter K (1991) The dynamics of avalanches of granular materials from initiation to runout. Part l: analysis. Acta Mech 86:201-223

Sorbino $G$ (2005) Numerical modelling of soil suction measurements in pyroclastic soils. In: Tarantino A, Romero E, Cui YJ (eds) Int. Symp. Advanced Experimental Unsaturated Soil Mechanics. Taylor \& Francis Group, London, pp 541-547

Tarolli P, Borga M, Dalla Fontana G (2008) Analyzing the influence of upslope bedrock outcrops on shallow landsliding. Geomorphology 93:186-200

Wang FW, Sassa K, Fukuoka H (2003) Downslope volume enlargement of a debris slide-debris flow in the 1999 Hiroshima, Japan, rainstorm. Eng Geol 69:309330

Zienkiewicz OC, Chang CT, Bettess P (1980) Drained, undrained, consolidating dynamic behaviour assumptions in soils, Geotechnique 30:385-395

Zienkiewicz OC, Chan AHC, Pastor M, Shrefler BA, Shiomi T (1999) Computational Geomechanics. J. Wiley and Sons 